\title{
Infant and Young Child Feeding Practice and Associated Factors among Mothers/ Caretakers of Children Aged 0-23 Months in Asella Town, South East Ethiopia
}

\author{
Sasie $\mathrm{SD}^{1 *}$, Oljira $\mathrm{L}^{2}$ and Demena $\mathbf{M}^{2}$ \\ ${ }^{1}$ Federal Ministry of Health, Amanuel Mental Specialized \\ Hospital, Addis Ababa, Ethiopia \\ ${ }^{2}$ Haramaya University College of Health and Medical \\ Sciences, Department of Public Health, Harar, Ethiopia \\ *Corresponding author: Sileshi Demelash Sasie, \\ Research and Training Center of Amanuel Mental \\ Specialized Hospital, Addis Ababa, Ethiopia
}

Received: July 01, 2017; Accepted: J uly 26, 2017; Published: August 02, 2017

\begin{abstract}
Background: The global strategy for infant and young child feeding describes essential actions to protect, promote and support appropriate infant and young child feeding. Finding in the area of infant and young child feeding practice is low in Ethiopia. The aim of this study was to describe infant and young child feeding practices at Asella Town.
\end{abstract}

Methods: A community based cross-sectional study was conducted between October and November 2015 using both quantitative and qualitative methods. A questionnaire was administered to 421 mothers/caregivers of children aged 0-23 months. Focused group discussions were conducted in selected communities to assess parents practice to infant and young child feedings.

Result: Timely initiation and exclusive breast feed was $86.3 \%$ and $70 \%$ respectively. Minimum meal frequency (MMF) and minimum dietary diversity (MMD) was $53.8 \%$ and $23.6 \%$ respectively. Sex of child (AOR=1.5(1.13, $3.2)$ ), place of delivery $(A O R=1.77(1.02,3.06))$ and culturally acceptable time for initiation of complementary feeding $(A O R=4(1.75,9.47))$ was significantly associated with IYCF practice.

Conclusion: The IYCF practice of mothers/caregivers is good in the Town. However there is a need to develop health education intervention, targeting behavior change in the urban area regarding IYCF practices are essential.

Keywords: Infant; Young child; Feeding practice; Urban community

\section{Abbreviations}

CSA: Central Statistical Agency; EBF: Exclusive Breastfeeding; EHNRI: Ethiopian Health and Nutrition Research Institute; HEW: Health Extension Workers; HU: Haramaya University; IYCF: Infant and Young Child Feeding; MMF: Minimum Meal Frequency; PI: Principal Investigators; SPSS: The Statistical Package for the Social Sciences; UNICEF: United Nations International Children's Emergency Fund; WB: World Bank; WHO: World Health Organization

\section{Background}

Infant and young child feeding the first two years of life is base for growth and development of children's [1]. The first 1000 days of life from conception through the first two years of life is a window of opportunity due to the profound positive effect optimal nutrition have on the developing child and a damage sustained during this period is often permanent [2].

The global strategy for infant and young child feeding describes essential actions to protect, promote and support appropriate infant and young child feeding. It focuses on the importance of investing in this crucial area to ensure that children grow to their full potential free from the adverse consequences of compromised nutritional status and preventable illnesses [3]. Under nutrition usually occurs at the age of 3-18 months making the child's first two years of life are considered a critical window of opportunity for the prevention of growth retardation and under nutrition [4]. So at this age group appropriate interventions should be taken to ensure that children reach their full growth potential and to prevent irreversible stunting and acute under nutrition [5].

A 6.3 million Children under age five died in 2013, nearly 17000 every day [6] and worldwide about 10.9 million children less than five years die each year mostly due to preventable causes such as undernutrition, diarrhea, pneumonia, measles, malaria and HIV/AIDS [7]. The disease burden can be attributed to under-nutrition whereas malnutrition has been responsible, directly or indirectly, for $60 \%$ of the 10.9 million deaths annually amongst children under five year .Over $67 \%$ of these deaths are associated with inappropriate feeding practices and occur during the first year of life. Poor feeding practices are, therefore, are a major threat to social and economic development as they are among most serious obstacles to attaining and maintaining health of this important age group [8].

In 2013 , the under five-mortality rate in low-income countries was 76 deaths per 1000 live births while it was 6\% in developed countries. Reducing these inequities across countries and saving more children's lives by ending preventable child deaths are important priorities [9]. Malnutrition in sub-Saharan Africa contributes to high rates of childhood morbidity and mortality [10]. Fortunately, the EBF rate in sub-Saharan Africa has increased from 22\% to 30\% [11].
J Fam Med - Volume 4 Issue 5 - 2017

ISSN : 2380-0658 | www.austinpublishing group.com

Sasie et al. (C) All rights are reserved
Citation: Sasie SD, Oljira L and Demena M. Infant and Young Child Feeding Practice and Associated Factors among Mothers/Caretakers of Children Aged 0-23 Months in Asella Town, South East Ethiopia. J Fam Med. 2017; 4(5): 1122 
However, these rates are still low a focus should be given to prevent the lives of children from danger that is from morbidity, mortality and irreversible damages. This was the result of poor adherence to IYCF raises threat to child causing high morbidity and mortality [12]

In Ethiopia only half (52\%) of infants under six months of age were exclusively breastfed and only $4 \%$ of breastfed children in Ethiopia are receiving four or more food groups daily and are receiving the minimum number of feedings. Seventy five percent of children under six months are predominantly breastfed and 66\% under the age of two receive age-appropriate breastfeeding [13]. Exclusively breastfed infants are less likely to become ill with diarrhea, and less likely to die from diarrhea or other infections. In addition, an EBF infant was less likely to develop pneumonia, meningitis, and ear infections than non-breastfeed infants [14]. IYCF recommendations are given to promote child survival through interventions that are cost effective. Only child morbidity and mortality are reduced when mothers, families and caregivers comply and practice well with the national IYCF recommendations [15]. The findings from Delhi India complementary feeding prevalence was (17.5\%) [16]. A study done in Ethiopia also shows that complementary feeding practice is not the same in different parts of the regions. A community based crosssectional study, which is conducted in Mekelle in 2013, shows that complementary feeding prevalence was $62.8 \%$ [17] while in Harar in 2012 the prevalence was $54.4 \%$ [18]. Therefore, this study would fill the gap of current situation in mother's practices and related factors to national IYCF recommendations.

\section{Methodology}

\section{Study area, design and data collection}

The study was conducted in the South East Ethiopia, in Asella Town which is $175 \mathrm{~km}$ from Addis Ababa in, December, 2015.

The study design was a community based cross-sectional study using quantitative and qualitative methods of data collection.

All feeding practices for children were elicited using the 24-hour recall method, except for initiation of breastfeeding and exclusive breast-feeding, for which, historic recall was used. Research assistants were trained over a two day period and the quantitative study was conducted between October and November 2015.

\section{Study sample}

The mothers/caretakers of children 0-23 months were the primary targets. For the qualitative parts of the data, six FGD was conducted among mothers, fathers and grand mothers of age less than 60 years of children's aged 0-23. Two FGD for each was conducted. Each group had 6-12 participants.

\section{Sample size and sampling}

The sample size was determined using complementary feeding prevalence rates of Harar Town, 54.4\% [18], at 95\% CI and considering a non-response rate of $10 \%$, the minimum required sample size was estimated to be 421 .

\section{Sampling}

Among a total of eight and then households were selected by randomly. Proportional to population size allocation technique was used in the determination of the number of study participants included in each selected kebeles. The selection was conducted using simple random sampling methods by drawing lottery. FGD was conducted among mothers, fathers and grand mothers of age less than 60 years of children's aged 0-23. Each group had 6-12 participants. These participants were selected purposively.

\section{Data management and analysis}

Quantitative data analysis: The data were entered in to EPI info version 3.5.4 software and then exported and analyzed by SPSS version 20 for windows. The bivariate analysis was done to see the association between dependent and independent variable at $\mathrm{p}$ value $<0.2$ to build a multiple variable model. Finally multivariate logistic regression analysis was employed to control for possible confounding effects and to assess the separate effects of each variable at p-value of $<0.05$ to declare statistical associations.

Qualitative data analysis: Data from focus group discussions was transcribed from Afan Oromo to English, responses were arranged in general categories that were identified in the discussion guide then it was coded. Common themes were identified, inferences were made from each theme, the transcript and notes were cleaned and saved in plain text file, and conclusion was drawn then triangulated with the data from the questionnaire.

\section{Ethics}

Ethical clearance was obtained from Institutional Health Research Ethics Review Committee (IHRERC) Haramaya University and permission was obtained from the Asella Town Health Bureau. Written consent to participate in the study was secured before conducting the interview and discussion.

\section{Results}

\section{Mothers'/care takers and husbands' demographic and socio-economic characteristics}

Of four hundred and twenty one (421) sampled mothers, 410 were successfully included in the study making the response rate of $97.4 \%$. Biological mothers accounted for 393(95.8\%) of caregivers, while $17(4.2 \%)$ were other caregivers such as grandmothers and sisters. The child's birth order ranged from 1-6 and majority 245(59.8\%) of the children were subsequent born while only $165(40.2 \%)$ were first born. Majority 376(91.6\%) of the children were born at health facility by health professionals (Table 1).

\section{Sources of information and support for IYCF}

Majority $352(85 \%)$ of the mothers stated that they had a role model of a breast feeding mother during their teenage either through own mother, a close relative or neighbor. Almost all mothers had received support for their IYCF practices and the findings are depicted as; key person supporting through words of praise, and opportunity to discuss IYCF. About a third 227(55.4\%) received from HEW, Own mother 105(26.3\%), child's father 44(10.5\%) and as key persons who supported BF through praising the mothers for their efforts and $295(72 \%)$ of the mothers stated that popular culturally accepted time to introduce complementary food was at six months of age (Figure 1).

\section{Mothers' IYCF practices}

As per the finding of this study initiation of breastfeeding within an hour of delivery was done by majority $354(86.3 \%)$ of the mothers, 
Table 1: Mothers' Childs and Childs fathers' back ground characteristics of IYCF practice in Asella Town, 2015.

\section{Mothers' demographic characteristics}

\begin{tabular}{|c|c|c|}
\hline \multicolumn{2}{|c|}{ Mothers' demographic characteristics } \\
\hline Age of mother & Number & Percent \\
\hline Below 20 & 34 & 8.3 \\
\hline $20-29$ & 229 & 55.9 \\
\hline $30-39$ & 128 & 31.2 \\
\hline Above 40 & 19 & 4.6 \\
\hline Total & 410 & 100 \\
\hline Marital status & & \\
\hline Single & 36 & 8.8 \\
\hline Married & 343 & 83.7 \\
\hline
\end{tabular}

\begin{tabular}{|c|c|c|}
\hline Married & 343 & 83.7 \\
\hline Divorced/Separated & 18 & 4.4 \\
\hline Widowed & 13 & 3.2 \\
\hline
\end{tabular}

\begin{tabular}{|c|c|c|}
\hline Total & 410 & 100 \\
\hline Educational level & & \\
\hline No formal education & 26 & 6.3 \\
\hline Primary education & 127 & 31 \\
\hline
\end{tabular}

\begin{tabular}{|c|c|c|}
\hline No formal education & 26 & 6.3 \\
\hline Primary education & 127 & 31 \\
\hline Secondary education & 134 & 32.7 \\
\hline College/ University & 14 & 26.6 \\
\hline Total Mothers & 410 & 100 \\
\hline
\end{tabular}

\begin{tabular}{|c|c|c|}
\hline College/ University & 14 & 26.6 \\
\hline Total Mothers & 410 & 100 \\
\hline Occupation of mothers & & \\
\hline House wife & 219 & 53.4 \\
\hline Government & 108 & 26.3 \\
\hline Self employee & 65 & 15.9 \\
\hline Student & 16 & 3.9 \\
\hline
\end{tabular}

\begin{tabular}{|c|c|c|}
\hline Government & 108 & 53.4 \\
\hline Self employee & 65 & 15.3 \\
\hline Student & 16 & 3.9 \\
\hline Total & 410 & 100 \\
\hline Religion & & \\
\hline Orthodox & 203 & 49.5 \\
\hline
\end{tabular}

\begin{tabular}{|c|c|c|}
\hline Religion & & \\
\hline Orthodox & 203 & 49.5 \\
\hline Muslim & 143 & 34.9 \\
\hline Catholic & 34 & 8.3 \\
\hline Protestant & 29 & 7.1 \\
\hline Total & 410 & 100 \\
\hline
\end{tabular}

\begin{tabular}{|c|c|c|}
\hline Total & 29 & 7.1 \\
\hline Childs age & 410 & 100 \\
\hline $0-6$ & & \\
\hline $23-J u l$ & 124 & 30.2 \\
\hline Total & 286 & 69.8 \\
\hline Sex of child & 410 & 100 \\
\hline
\end{tabular}

\begin{tabular}{|c|c|c|}
\hline Total & 410 & 100 \\
\hline Sex of child & & 52.4 \\
\hline Female & 215 & 47.8 \\
\hline Total & 195 & 100 \\
\hline Occupation of father & 410 & \\
\hline Government employee & & 40 \\
\hline Self employee & 144 & 53.5 \\
\hline Others & 191 & 6.2 \\
\hline Total & 22 & 100 \\
\hline Education of fathers & 357 & 2.2 \\
\hline No education & 8 & 17.9 \\
\hline Primary education & 64 & 34.9 \\
\hline Secondary education & 123 & 28 \\
\hline Diploma & 100 & 17.4 \\
\hline Degree and above & 62 & \\
\hline Total & 357 & \\
\hline
\end{tabular}

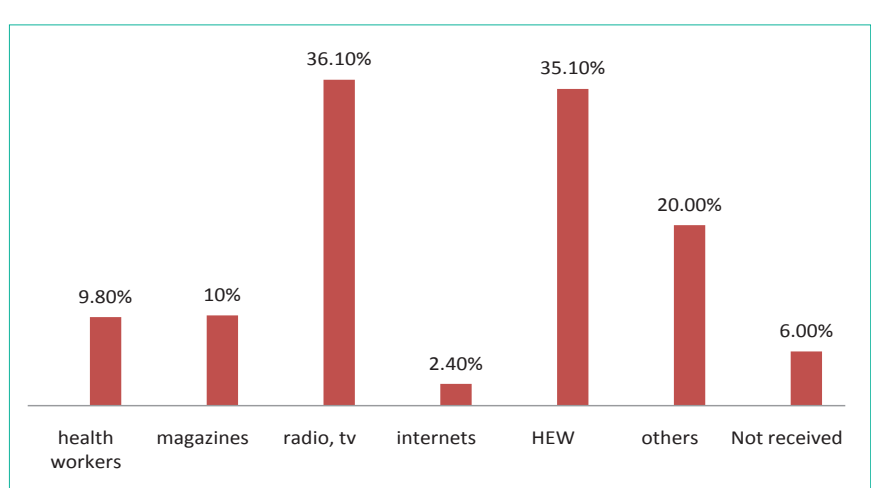

Figure 1: Source of information for IYCF practice in Asella Town, 2015.

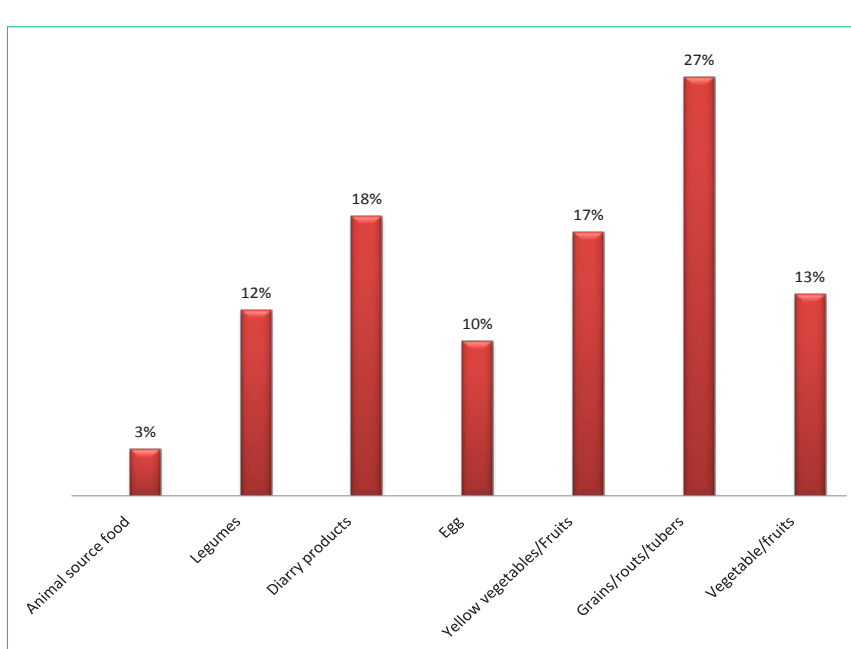

Figure 2: Food diversity given to children aged 7-24 months in Asella Town, 2015.

$70 \%$ of them were exclusively breastfed and almost all 392(95.6\%) of the respondents had continued breastfed their children.

Mothers' practice of complementary feeding that was assessed in this study included: the practice of timely initiation of liquids, semisolids and soft foods, dietary diversity, minimum meal frequency and consumption of iron rich foods. A proportion of 287(91.1\%) of the mothers initiated liquids, semi-solids and soft foods at six months of life. Minimum meal frequency was found to be adequate $53.8 \%$ of children aged 0-23 months. 108(26.3\%) of children aged 7-24 months had received four or more of food groups as per the recommendations. Consumption of animal origin foods was low (3\%), grain/tubers was $27 \%$ and children that consumed eggs was $10.0 \%$ while consumption of dairy products was $18 \%$ (Figure 2). However, majority of the family were not aware of dietary diversity as it was indicated in FGD. A 23years old mother discussant replied saying, "...no one worried about the variation of food types, and the basic thing ability to feed the baby with any food we think is easy to find and preferred by the child, sometimes those who have ability to afford may keep variation with unknown frequency or irregular frequency of variation ..."

All variables that have a p-value of less 0.2 (at significant level of $95 \% \mathrm{CI}$ ) with outcome variable in the bivariate logistic regression were included in the multivariate regression models. Place of delivery $(\mathrm{AOR}=1.8(1.08,3.25))$, sex of child $(\mathrm{AOR}=1.9(1.13,3.2))$ and popular culture for timely initiation of complementary food $(\mathrm{AOR}=4(1.75$, 
Table 2: A bivariate and multivariate analysis of determinants of IYCF recommendation in Asella Town, 2015.

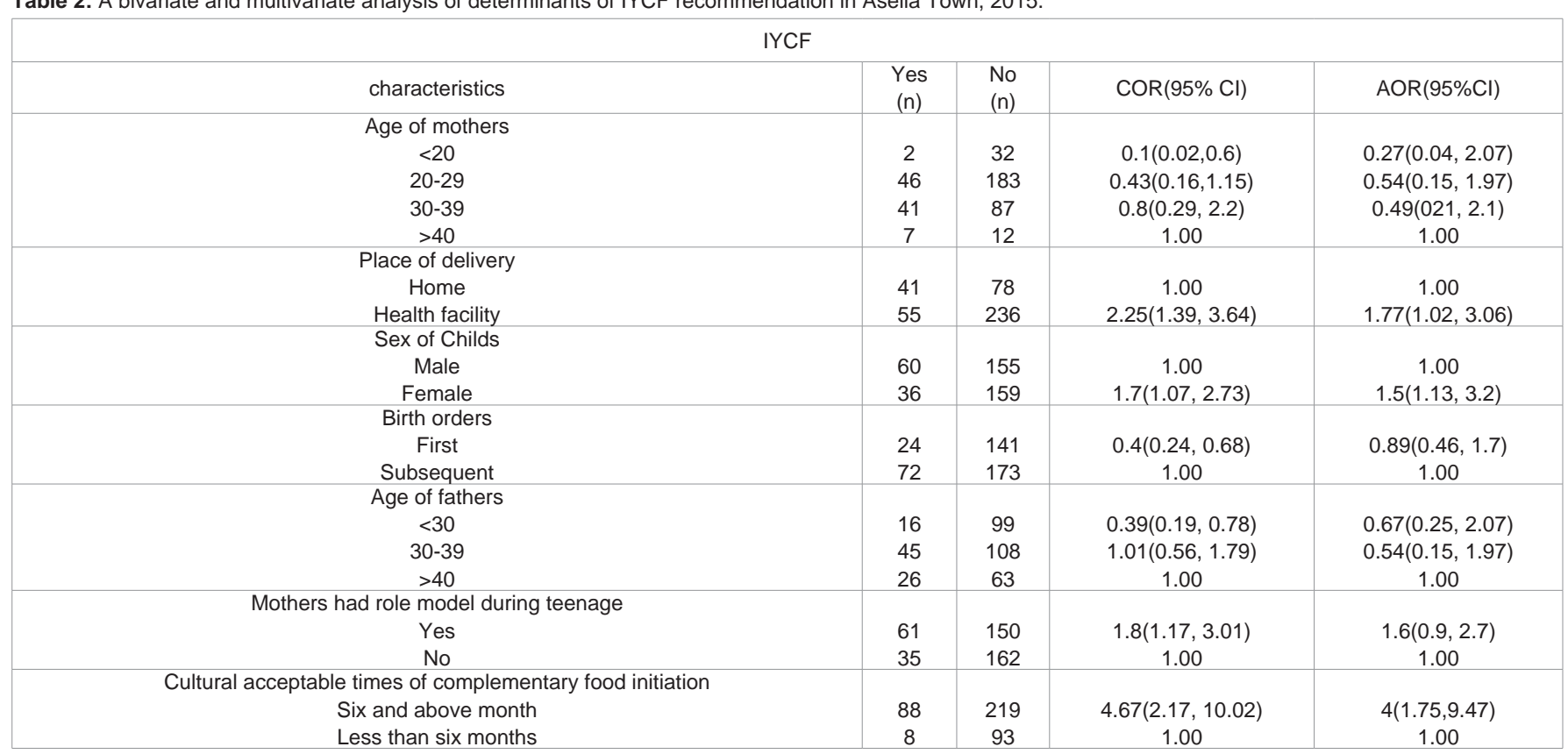

9.47)) had independent association with practice of the national IYCF recommendations. A child who delivered at health facility had 1.8 more likely to have practice of IYCF than those delivered at home. Being female had 1.5 times more likely to have a better practice of IYCF recommendation than male child's did (AOR=1.5(1.13, 3.2)). Mothers/care takers who had culturally acceptable times of six month and above were 4 times more likely to practice the recommendation than below six months $(\mathrm{AOR}=4(1.75,9.47))$. The rest of the variables and background characteristics have no independent association to the national IYCF recommendations as shown in Table 2.

\section{Discussions}

As per the finding of this study, the high percentage 343(83.7\%) of married respondents is an indication that the children are raised in a family units. Family level intervention would be a good area to bring out the full potential of fathers support and involvement in IYCF. The findings of this study suggest that marital status as well as age of mothers had no significant association with IYCF practice , but other study shows that married women $[\mathrm{AOR}=2.490$; 95\% CI: $(1.170,5.301)]$ were positively associated with timely initiation of complementary feeding [19] this may be due to the study area was urban.

Being female were 1.5 more likely and positively associated with the recommendation than being male child ( $\mathrm{AOR}=1.5(1.13$, 3.2)). Similarly, a study conducted in India shows that females were breastfed frequently during nights than males, although set in a different cultural circumstance, has found that male infants are weaned earlier than the female infants [20].

Mother who gave birth at health facility were1.7 more likely practice IYCFR and positively associated $(\mathrm{AOR}=1.7(1.02,3.06))$ which is similar with the finding of a study done in Mekele that mothers who delivered at home $(\mathrm{AOR}=0.338(0.12,0.99)$ ) were negatively associated with timely initiation of complementary feeding
[21] and the findings of that was done by [22] mothers who delivered at health facility were 2.3 times more practice breast-feeding than delivered at home $(\mathrm{AOR}=2.30(0.69,0.71))$. Qualitatively an FGD of father strongly supports the mother to deliver her baby at health facility A 45 years old discussant assertively replied, “...during pregnancy husbands provide especial care to their wives, we have one proverb '...the wife is queen and the husband is servant...' that is to mean husbands serve their wife on house hold activities, they take the role of female and purchase honey, butter, milk and other important food for her, fetch water, keep her hygiene, take her to health facility to protect the life of their beloved wife and baby by health professional --- continue saying-this can helps my baby to be well fed, healthy and grow faster ..."

Majority of the mothers had the opportunity to make choices of how to feed their infants from the position of having received information about IYCF. 148(36.1\%) of mothers had received IYCF information from radio and TV stations, 144(35.1\%) from extension health workers and others from health care providers, magazines, and internet. This finding was similar with the finding of [23] of Ethiopia as majority of mothers receive IYCF information from health workers, mass media and HEW. In Kenya shows similar findings as the IYCF information was received from mass media (all Radio and television stations (3\%)), Community Health Nurse (28.9\%), magazines (5\%), books (4\%) and internet (1.9\%) while $15.4 \%$ of the mother had never received IYCF information [18].

An FGD result also supports this idea as: A 40 year's old discussant replied, "I think the main source of information in our area is health extension workers and health care providers." The other discussants also show their agreement by nodding their head. This would mean improving the health facilities interventions in place to address the gap is essential for effective implementations of IYCF recommendation. Similarly, a 23years old breastfeeding mother said:

"Yes the HEWs informed or teach our community about the time to 
initiate or start additional food. They teach the community on different community gatherings events that the children have to start additional food such as milk and easily digestible food after six months of age." The other discussants show their agreement by nodding their head.

Majority of mothers 295(72\%) of the mothers stated that popular culturally accepted time to introduce complementary food was at six months of age and it was positively and significantly associated $(\mathrm{AOR}=4(1.75,9.47))$ with IYCF practices. Mothers culture that start complementary food at six month and above were 4 times more likely to practice well the recommendation than those start below six months. similarly the study conducted in Ethiopia in 2010 shows the ways a community nourished their young children are the result of generations of tradition, and many traditional feeding practices are linked to cultural and even spiritual beliefs [2]. An FGD result also shows that: A 28years old discussant replied saying, "...previously our culture hurt us due to lack of knowledge, breast feeding were initiated at least one to two days after delivery, believing that the mother cannot produce breast milk immediately after delivery, but currently we do not have this kind of tradition in our locality mothers start breast feeding right after delivery and continued for successive six months..."

As a global public health recommendation, the strategy for infant and young child feeding describes essential actions to protect, promote and support appropriate infant and young child feeding. Exclusive breast-feeding for the first 6 months of life followed by complementary feeding along with breast-feeding as per demand of the child is the recommendation for optimal growth and development of children under 2 years of life. Thereafter, to meet their evolving nutritional needs, infants should receive safe and nutritionally adequate complementary foods while breastfeeding continues for up to two years of age or beyond [6].

The Present study revealed those mothers who practice the IYCF accordance to the recommendation was $23.4 \%$, which was relatively higher than the national level of $4 \%$. This can be due to the active engagements of the HEW in Asella Town that can transmit the IYCF information and due to the fact that the national level was conducted only from 6-23 months of age. Timely initiation of breast milk within one hour of delivery was $354(86.3 \%)$ which was better than the national level result of Ethiopia 66.9\% [2]. This may be attributed to the fact that majority 376(91.7\%) of the mothers had given birth in health facilities and better performance of health extension workers. The health facility had the mandate to ensure the implementation of National IYCF recommendations (FMOH IYCF recommendations).

To ensure practice, the infant had put on the breast within the first hour after delivery ensured by the health care provider in attendance of the delivery. The breast-feeding practice prevalence rates revealed in this study was 392(95.6\%) showing that it was universal as also seen in other studies findings done in Ethiopia by [23] and [17]. About $287(70 \%)$ of mothers had started complementary feeding at sixth month of the child's age, as recommended. It was higher than the findings from Delhi India 17.5\% [16], Mekelle 62.8\% [17], Ethiopia with national level 51\% and Harar 54.4\% [18] but less than Abiyi Ayidi North west of Mekele 80\% [22].

Complementary feeding was done with a wide initiation of solid, semi-solid and soft foods at six months of life, minimum meal frequency and Minimum dietary diversity. Introduction of solids, semi-solid and soft foods may not be the same due to a varied source of information given to mother/care givers.

Minimum meal frequency was found to be adequate $53.8 \%$ of children, which was higher than a study done in Gojam 50.4\% [24] and $49 \%$ at national level of Ethiopia [13]. Similar study conducted in Delhi India shows that it was (48.6\%) [25] and 48.6\% in Kolkata which is in west Bengal of India Repetitive counseling and education may easily help to increase the adequacy.

Minimum dietary diversity was found to be adequate in only 26.3\% of children which was higher than the national level result 7.1\% (Ali .D, 2012) and 12.6\% Gojam [24] and Abiyi Ayidi North West of Mekele [22] was $11.9 \%$. It was less than the finding of study in Delhi $32.6 \%$ [26] and less than West Bengal 43.4\% [27]. The following FGD result demonstrates the family practice of providing complementary foods: A 36years old discussant strongly replied, “...yes, though all community members do not have equal economic capacity, each house hold have at least hen and they can provide egg for the baby. Food types such as milk, honey, butter, banana and orange may need to be purchased from the market."

Proportion of children 6-23 months of age who receive an ironrich food or iron-fortified food. For infants and young children, or that is fortified in the home was $47.3 \%$ that is especially designed better than the national study of Ethiopia $8.9 \%$ while in Kenya children of aged 0-23 who had received Iron was $13.6 \%$ [27]. However, it was less than that of Zambia 59.5\% [2]. This was the result of the active engagement of health care providers and HEW on their routine activity.

\section{Conclusion}

The findings of this study have clearly indicated that there is a gap between optimal infant and young child feeding practices and national recommendation. There are external and systematic challenges to improving behaviors, but with well trained and motivated health workers, as well as coordinated and targeted messaging in communities to caregivers especially mothers/caretakers a great deal of progress can be made towards optimal infant feeding practices for improved health of children under two years of age.

Based on the finding of the study; it has been concluded that:

1. IYCF practice status of mothers in Asella Town was higher relative to national recommendation.

2. IYCF practice was influenced by place of delivery, sex of children's and culturally acceptable times of initiations of foods.

3. Mother who had received IYCF information and support by health extension worker had better practices of IYCF as it was mentioned on FGD.

IYCF information delivered by health extension worker and health service providers should be strengthened; the health bureau has to improve the capacity of the health extension workers effort of supporting IYCF and the policy makers need to come up with IYCF policies that would reach the mothers in the community with practical IYCF intervention especially during initiation of complementary feeding and breast-feeding. 


\section{Declaration}

\section{Ethics approval and consent to participate}

Ethical approval was obtained from Haramaya University, College of Health and Medical Sciences, Institutional Health Research Review Ethics Committee (IHRREC). A signed written consent was also obtained from the participants before commencement of any data collection (interview).The data were not accessed by a third person, except investigators, and was kept confidentially.

\section{Availability of data and material}

The datasets during and/or analyzed during the current study is available from the corresponding author on reasonable request.

\section{Acknowledgement}

My gratitude goes to Amanuel Mental Specialized Hospital and Federal Ministry of Health for awarding me to pursue my study and Haramaya University for allowing me to participate in this area.

Finally, my gratitude goes to my wife Yeshi Taye, you are the moon that gives light for the successful accomplishment of this course, and I would like to thank you once again.

I would also thank to the study participants for the cooperation.

\section{References}

1. Lamberti. L and Black. R. Breast-feeding and risk for diarrhea, morbidity, and mortality. BMC Public Health. 2011; 11: 15.

2. Ali D. Alive \& Thrive. Practices, IYCF practices, beliefs, and influences in SNNP region, Ethiopia. 2010, Survey report.

3. EH NRI. Assessment of status of infant and young child feeding practice policy and programmatic achievements and gap. Workshops on Assessment of status of infant and young child feeding practice, policy and programmatic achievements and gaps, November 12-16, 2012, Addis Ababa Ethiopia.

4. Victora $\mathrm{C}$, Hallal $\mathrm{P}$, Blossner $\mathrm{M}$ and Shrimpton R. Worldwide timing of growth faltering: revisiting implications for interventions. Journal of Pediatrics. 2010; 125: 473-480.

5. Dewel G. Systematic review of the efficacy and effectiveness of complementary feeding interventions in developing countries. Maternal and Child Nutrition. 2008; 4: 24-85.

6. WHO. Strengthening action to improve feeding of infants and young children 6-23 months of age in nutrition and child health programs': report of proceedings, Geneva, 6-9 October 2008. Geneva: World Health Organization.

7. UNICEF. The state of the world's children 2009. Maternal and Newborn health. Global challenge US fund for UNICEF Youth report, the state of the world's children, 2008.

8. WHO. Infant and young child feeding (IYCF) Model. Model Chapter for textbooks for medical students and allied health professionals. 2009.

9. Aaaa.
10. Olack B, Burke $\mathrm{H}$ and Cosmos L. Nutritional status of under-five children living in an informal urban settlement in Nairobi, Kenya. Journal of Health, Population, And Nutrition. 2011; 29: 357-363.

11. UNICEF. Progress for children: a world fit for children. 2007, Statistical Review Number 6. UNICEF, New York.

12. WHO. Strengthening nutritional status of mother and children especially in nutrition and child health programs': report of proceedings, Geneva, 6-9 October 2007. Geneva: World Health Organization.

13. CSA. National nutrition survey by central statically agency of Ethiopi, 2011

14. FMOH, 2004. Federal Ministry of Health, Family Health Department Ethiopia: National strategy for infant and young child feeding. Addis Ababa: Federal Ministry of Health, Family Health Department Ethiopia; 2004.

15. Nduati R. Supporting women to practice safe infant feeding: Kenya a case Study of the African experience. Paper presented at breast conferences. December $8^{\text {th }}, 2012$, Wellstart.

16. Chand D. Complementary Feeding-Reasons for Inappropriateness in Timing, Quality and consistency. Indian Journal of Pediatric. 2008; 75: 49-56.

17. Berhane Yitages. Timely initiation of complementary feeding and associated factors among children aged 6 to 12 months in Northern Ethiopia: an institution-based cross-sectional study. BMC Public Health. 2013; 13: 1050.

18. Kume Abera. Infant and Young Child Feeding Practices among Mothers Living In Harar, Ethiopia. Harar Bulletin of Health Science. 2012; 4: 66-78.

19. Dessalegn Tamru. Survey on the introduction of complementary foods to infants within the first six months and associated factors in rural communities of Jimma Arjo. International Journal of Nutrition and Food Sciences. 2013 2: $77-84$

20. Marie S. Breast feeding practices among Saharawi women in the Algerian refugee camps. 2013; Final thesis for partial fulfillment of masters Degree.

21. Samson Yemane. Timely initiation of complementary feeding practice and associated factors among mothers of children aged from 6 to 24 months in Axum town, north Ethiopia. International Journal of Nutrition and Food Sciences. 2014; 3: 438-442.

22. Ergib Mekbib. Magnitude and factors associated with appropriate complementary feeding among mothers having children 6-23 months-of-age in Northern Ethiopia; a community-based cross-sectional study. Journal of Food and Nutrition Sciences. 2014; 2: 36-42.

23. Amanuel Birhanu. Mother's Knowledge on Nutritional Requirement of Infant and Young Child Feeding in Mekelle, Ethiopia. Global Journal of Medical research. 2013; 13: 9-13.

24. Melkamu Beyene. Dietary diversity, meal frequency and associated factors among infants and young children aged 6-23 months in Dangila town, Northwest Ethiopia, 2014.

25. Amir M. A study on IYCF practice among mothers attending an Urban Health Center in East Delhi, 2013.

26. Aparajita D. Assessment of Infant and Young Child Feeding Practices among the Mothers in a Slum Area of Kolkata: A Cross Sectional Study. International Journal of Biological \& Medical Research original articles. 2010; 3855-3861.

27. Jacob K. Determinants of complementary feeding practices and nutritional status of children 6-23 months old in korogocho slum, Nairobi County, Kenya, 2010.
J Fam Med - Volume 4 Issue 5 - 2017

ISSN : 2380-0658 | www.austinpublishinggroup.con

Sasie et al. (C) All rights are reserved
Citation: Sasie SD, Oljira L and Demena M. Infant and Young Child Feeding Practice and Associated Factors among Mothers/Caretakers of Children Aged 0-23 Months in Asella Town, South East Ethiopia. J Fam Med. 2017; 4(5): 1122 